\title{
Simulation of particle formation and number concentration over the Eastern United States with the WRF-Chem + APM model
}

\section{G. Luo and F. Yu}

Atmospheric Sciences Research Center, State University of New York, 251 Fuller Road, Albany, New York 12203, USA

Received: 28 April 2011 - Published in Atmos. Chem. Phys. Discuss.: 12 May 2011

Revised: 19 August 2011 - Accepted: 9 November 2011 - Published: 21 November 2011

\begin{abstract}
Aerosol nucleation events, widely observed at various locations around the globe, are a significant source of cloud condensation nuclei $(\mathrm{CCN})$ which determines aerosol indirect radiative forcing. In this study, a size-resolved, computationally efficient, advanced particle microphysics (APM) model, which has been previously incorporated into a global chemistry transport model (GEOS-Chem), is integrated into the Weather Research and Forecast model coupled with Chemistry (WRF-Chem) to study new particle formation and its contribution to particle number concentration and CCN abundance over the Eastern United States. Sizeand composition-resolved aerosol properties from GEOSChem + APM simulations are used to initialize and provide boundary conditions for the WRF-Chem + APM model. The modeling results have been evaluated with the relevant measurements obtained during the INTEX-A field campaign in the summer of 2004. Model simulation captures the high concentrations of $\mathrm{SO}_{2}$ and $\mathrm{CN1} 10$ at surface layer and source regions but underpredicts the values in the upper troposphere. The particle formation and number concentrations simulated by WRF-Chem + APM are generally consistent with those based on GEOS-Chem + APM over the Eastern United States, but the WRF-Chem + APM simulation has a much higher spatial resolution and can reveal urban and even plume scale processes. Our simulations show that high values of nucleation rates are largely confined to the regions of high $\mathrm{SO}_{2}$ emissions and that aerosol nucleation dominates the spatial and temporal distributions of condensation nuclei lager than $10 \mathrm{~nm}(\mathrm{CN} 10)$. Similarly, high concentrations of $\mathrm{CCN}$ at supersaturation of $0.4 \%$ (CCNO.4) are generally confined to $\mathrm{SO}_{2}$ source regions, with the highest monthly (July) mean CCNO.4 value exceeding $1600 \mathrm{~cm}^{-3}$ in the lower
\end{abstract}

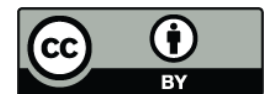

Correspondence to: $\mathrm{G}$. Luo

(ganluo@asrc.albany.edu) troposphere over Indiana and Ohio. Nucleation and subsequent growth of secondary particles are important sources of CCN0.4, accounting for more than $80 \%$ in most parts of the Eastern United States.

\section{Introduction}

Atmospheric aerosols can substantially reduce the surface solar irradiance, alter the vertical solar heating profile and cloud properties, suppress precipitation, and modify the hydrological cycle (Atwater, 1970; Twomey, 1977; Albrecht, 1989; Charlson et al., 1992; Pincus and Baker, 1994; IPCC, 2007; Luo et al., 2009). The impact of aerosols on the Earth's climate depends strongly on the particle properties (size distribution, composition, and mixing state), and is a major source of uncertainties in weather and climate predictions (Pan et al., 1998; Dusek et al., 2006; Clarke and Kapustin, 2010). At a given supersaturation ratio, cloud condensation nuclei $(\mathrm{CCN})$ concentrations which are important for aerosol indirect radiative forcing are largely controlled by the number size distribution and composition of atmospheric particles. Dusek et al. (2006) suggested that the aerosol number size distribution may play an important role in the determination of the particles' ability to act as CCN. Most previous weather and climate models only consider particle chemical composition, and few regard particle size distributions. In view of the importance of particle size information in assessing the impact of aerosols on climate and the environment, more and more works began to consider size-resolved aerosol microphysics in regional (Fast et al., 2006; Gustafson et al., 2007; Zaveri et al., 2008; Chapman et al., 2009; Zhang et al., 2010a) and global (Spracklen et al., 2008; Pierce and Adams, 2009; Wang and Penner, 2009; Yu and Luo, 2009) models. 
The WRF-Chem model opens new possibilities for studying the interactions of meteorology, aerosol, cloud, radiation, and chemistry in a fully interactive manner over a wide range of spatial and temporal scales (e.g. Fast et al., 2006). WRFChem v3.1.1 includes three choices for aerosol models which are the Goddard Chemistry Aerosol Radiation and Transport (GOCART) model, the Modal Aerosol Dynamics Model for Europe incorporated with the Secondary Organic Aerosol Model (MADE/SORGAM) and the Model for Simulating Aerosol Interactions and Chemistry (MOSAIC). GOCART does not include aerosol microphysics. MADE/SORGAM uses three lognormally-distributed modes (the Aitken, accumulation and coarse modes) to simulate particle size distribution, while MOSAIC uses a sectional approach where aerosol size distribution is divided into discrete size bins defined by their lower and upper dry particle diameters. MOSAIC has been widely used in WRF-Chem studies (Fast et al., 2006; Gustafson et al., 2007; Zaveri et al., 2008; Chapman et al., 2009). The implementation of MOSAIC improves WRF-Chem's ability in studying aerosol related problems; however, MOSAIC has limited capacity in modeling new particle formation and predicting $\mathrm{CCN}$ number concentration. For example, the two nucleation schemes considered in the publically released version of MOSAIC are $\mathrm{H}_{2} \mathrm{SO}_{4}$ $\mathrm{H}_{2} \mathrm{O}$ binary homogeneous nucleation (BHN) from Wexler et al. (1994) and $\mathrm{H}_{2} \mathrm{SO}_{4}-\mathrm{NH}_{3}-\mathrm{H}_{2} \mathrm{O}$ ternary homogeneous nucleation (THN) from Napari et al. (2002). Recent assessment reported by Zhang et al. (2010b) indicates that these two nucleation schemes are kinetically incorrect and thus should not be used. Since nucleation is an important source of CCN which is essential for aerosol indirect effect calculation (e.g. Spracklen et al., 2006, 2008; Makkonen et al., 2009; Wang and Penner, 2009; Yu et al., 2010), more robust nucleation mechanisms with clear physics and state-of-the-art thermodynamics are apparently needed to improve the representation of the nucleation process in WRF-Chem. Another limitation of MOSAIC in studying nucleation and growth processes is its default size range and resolution. MOSAIC can be implemented in the sectional framework where the aerosol size distribution is divided into 4 or 8 discrete size bins. Even with 8 discrete size bins, the smallest size bin in MOSAIC is $59 \mathrm{~nm}$ which is much bigger than the sizes of freshly nucleated particles in the atmosphere (a few nanometers). There are many land-, ship-, and aircraft-based measurements which can provide the concentrations of condensation nuclei larger than $\sim 3(\mathrm{CN} 3)$ or larger than $10 \mathrm{~nm}(\mathrm{CN} 10)$ (see Yu et al., 2010 and references therein). Thus current MOSAIC particle size ranges are not suitable for using these data to constrain the modeling of aerosol number concentrations. Furthermore, the current version of MOSAIC only employs 2 size bins to represent particles smaller than $150 \mathrm{~nm}$ and thus does not have high enough size resolution to study the growth of nucleated particles $(\sim 1.5 \mathrm{~nm})$ to $\mathrm{CCN}(\sim 30$ $90 \mathrm{~nm})$.
We have recently studied detailed particle formation and growth processes in a global chemistry transport model (GEOS-Chem) using an advanced particle microphysics (APM) model (Yu and Luo, 2009). The APM model, designed specifically for studying the contribution of secondary particles to $\mathrm{CCN}$ abundance, employs 30 sectional bins to represent particles in the range of $1.2 \mathrm{~nm}$ to $120 \mathrm{~nm}$ (in addition to 10 bins used to represent particles in the size range of $120 \mathrm{~nm}-12 \mu \mathrm{m})$. The APM model employs stateof-the-science, ion-mediated nucleation (IMN) theory ( $\mathrm{Yu}$ and Turco, 2000; Yu, 2010a) which has been supported, as shown in detailed and well constrained case studies (Yu and Turco, 2011), by recent state-of-the-art multiple-instrument characterization of nucleation processes including the charging state of freshly nucleated particles (e.g. Kulmala et al., 2007). The new particle formation and particle number concentrations predicted by the APM model in the framework of GEOS-Chem have been extensively evaluated against a wide range of land-, ship-, and aircraft- based measurements (Yu and Luo, 2009, 2010; Yu et al., 2010).

In this study, we seek to improve simulations of the aerosol formation and growth processes in WRF-Chem by incorporating the same APM used in GEOS-Chem into the framework of WRF-Chem. The resulting model is then used to study the evolution of size-resolved secondary and primary particle properties in the atmosphere over the Eastern United States. In Sect. 2, the details of the coupled model and key features are described. Section 3 presents model configuration, the comparisons with measurements, and results. Section 4 is the Summary and Discussion.

\section{Description of models, approaches, and key features}

\subsection{The WRF-Chem model}

The Weather Research and Forecast/Chemistry model (WRF-Chem) is an online-coupled, multi-scale, meteorology, atmospheric chemistry model which can simulate meteorology-chemistry-aerosol-cloud-radiation feedbacks via direct, semi-direct and indirect effects. Biogenic and anthropogenic emissions, convective and turbulent chemical transport, photolysis, advective transport, dry deposition, and wet scavenging are all treated simultaneously with the online meteorology. All transport processes related to atmospheric composition can be done by the WRF meteorological model with the same horizontal and vertical coordinates. The same physics parameterizations for sub-grid scale transport are used in this model where as horizontal and vertical interpolation in time is not needed.

The WRF-Chem model version 3.1.1, which is employed in this study, includes several gas-phase mechanisms (e.g. Regional Acid Deposition Model, version 2 (RADM2) (Stockwell et al., 1990) and Carbon-Bond Mechanism version Z (CBM-Z) (Zaveri and Peters, 1999) through the 
use of the Kinetic Pre-Processor (KPP) and several aerosol modules (e.g. the Modal Aerosol Dynamics Model for Europe (MADE) with the secondary organic aerosol model (SORGAM) of Schell et al. (2001) as well as the MOSAIC sectional model aerosol parameterization, Zaveri et al., 2008). The Madronich, Fast-J Photolysis, and or FTUV scheme can be chosen for the photolysis calculation. WRFChem version 3.1.1 can simulate the mass concentrations of particles of different types or compositions and treat sizeresolved aerosol microphysics within the MOSAIC model which uses either 4 or 8 bins for various aerosols covering a dry diameter range of $0.059-10 \mu \mathrm{m}$. A detailed description of the model (including the treatment of various emission sources, chemistry and aerosol schemes) can be found in the model website (http://ruc.noaa.gov/wrf/WG11) and the WRF-Chem version 3.1 Users Guide (http://ruc.noaa.gov/ wrf/WG11/Users_guide.pdf).

\subsection{Advanced Particle Microphysics (APM) model}

The multi-type, multi-component, size resolved APM model is the result of past development and validation efforts aimed at explaining atmospheric particle observations (e.g. Turco et al., 1979; Toon et al., 1988; Jacobson et al., 1994; Jacobson and Turco, 1995; Yu and Turco, 1997, 2011; Yu, 1998, 2006; Yu and Luo, 2009). The basic microphysical processes which are resolved in the model include nucleation, condensation/evaporation, coagulation and thermodynamic equilibrium with local humidity. The APM model employs an up-to-date kinetically consistent IMN model incorporating recently available thermodynamic data and schemes (Yu, 2010a) to quantify the spatial and temporal variations of secondary particle formation and its contribution to total particle number concentration and $\mathrm{CCN}$ abundance throughout the atmosphere. The APM model is also versatile, in that the number of bins (sections), compositions, and types of aerosols can be easily specified. APM contains a number of computing efficiency algorithms, including the extensive usage of pre-generated lookup tables and variable time steps for different microphysical processes (Yu and Luo, 2009).

\subsection{WRF-Chem coupled with the APM model: key features}

In order to improve our understanding of the impact of aerosols on regional climate, the size-resolved aerosol microphysics has to be handled properly within the regional meteorology-chemistry-aerosol-cloud-radiation model. In this study, the WRF-Chem (version 3.1.1) coupled with the APM model is used to simulate the size-resolved microphysics for primary and secondary particles over the Eastern United States. We do not consider the feedback of aerosols on radiation in this work. The formation of new particles is determined by the IMN mechanism (Yu, 2010a). Contributions of nitrate and ammonium to sulfate particle growth are considered through equilibrium uptake. Scavenging of secondary particles by other types of particles is also taken into account. The emission inventories and key features of the coupled model related to size-resolved aerosol microphysics are described below.

\subsubsection{Emissions}

Hourly anthropogenic aerosol and trace gas emissions are currently available for the contiguous 48 states of the United States, southern Canada and northern Mexico based upon the United States Environmental Protection Agency (EPA) National Emissions Inventory (NEI) from 2005. Area emissions are available on a structured $4 \mathrm{~km}$ grid, while point emissions are available by latitude and longitude locations. Area and point emissions for $\mathrm{SO}_{2}, \mathrm{NO}_{\mathrm{x}}, \mathrm{NH}_{3} \mathrm{VOC}$, primary black carbon and organic carbon (BCOC) are included in the database. The detailed description of NEI05 emission data can be found online at http://ruc.noaa.gov/wrf/WG11/ anthropogenic.htm.

Many investigations have suggested the importance of the assumptions of the mass fraction and size distribution of primary sulfate (sulfuric acid or sulfate formed in sub-grid anthropogenic $\mathrm{SO}_{2}$ plumes) in the modeling of aerosol particle number concentrations and CCN abundance (Spracklen et al., 2005; Wang and Penner, 2009; Luo and Yu, 2011). Primary sulfate emission parameterization is expected to have large uncertainty, and presently it is difficult to determine the correct value for sub-grid secondary sulfate particle formation (Luo and Yu, 2011; Yu, 2010b). Luo and Yu (2011)'s work indicated that the number concentrations of sulfate particles directly injected into the grid boxes decrease as primary sulfate emissions decrease, but that the rate of new particle formation near the source regions increase, and the inclusion of primary sulfate emissions does not improve agreement with the measurements. Therefore, in the present study, we assume that all anthropogenic sulfur emission is emitted as $\mathrm{SO}_{2}$ and no anthropogenic sulfur is emitted as primary sulfate particles.

The parameterization of Gong (2003) is employed to calculate the size-resolved sea salt emission. Size resolved dust emission is based on the scheme described in Zender et al. (2003) and D'Almeida (1987). Carbonaceous aerosol emissions mainly result from fossil fuel and bio-fuel combustion, and biomass burning. We assume that $20 \%$ of black carbon and $50 \%$ of organic carbon from anthropogenic emissions are hydrophilic and the rest are hydrophobic. As discussed in our previous work (Yu and Luo, 2009), BCOC from fuel combustion is assumed to have a lognormal distribution with number median diameter of $60 \mathrm{~nm}$ and standard deviation of 1.8, and BCOC from biomass burning is assumed to have a log-normal distribution with number median diameter of $150 \mathrm{~nm}$ and standard deviation of 1.8 . 


\subsubsection{Representation of major particles in the coupled model}

Bin resolution in the APM model can be varied so we can use a higher resolution for the size range of our interest. For the WRF-Chem + APM model, we use 40 sectional bins to represent sulfate (or secondary) particles covering dry diameters ranging from $0.0012 \mu \mathrm{m}$ to $12 \mu \mathrm{m}$. There are 30 size bins for $0.0012-0.12 \mu \mathrm{m}$ dry diameter range and another 10 size bins for $0.12-12 \mu \mathrm{m}$, providing a high resolution for the size range important to the growth of nucleated particles to CCN. We use 20 sectional bins to represent sea salt, covering dry diameters from 0.012 to $12 \mu \mathrm{m}$. Bin resolution is variable and 10 bins are used for $0.012-0.12 \mu \mathrm{m}$ (dry diameter) range and another 10 bins for $0.12-12 \mu \mathrm{m}$. 10 sectional bins are used in the model to represent dust for $0.12-12 \mu \mathrm{m}$. In the present study, we do not implement the size-resolved microphysics for primary BCOC. Primary BCOC particles generally have a log-normal distribution, and we derive the BCOC number concentrations from the simulated mass and assumed size distributions with 8 tracers following the same treatment in GEOS-Chem (Yu and Luo, 2009). In order to assess the relative contribution of secondary versus primary particles to $\mathrm{CCN}$ budget, the scavenging of secondary particles by primary particles has to be properly considered. In addition, the coating of primary particles by secondary species may significantly influence the optical and hygroscopic properties of primary particles. In the APM, secondary particles are separated from primary particles but the coating of secondary species on primary particles is considered (we termed such an aerosol system as "semi-externally mixed"). Via coagulation, condensation, and in-cloud oxidation, some of secondary species become part of primary particles (i.e. coating). The coating of primary particles by secondary species is simulated using 4 separate tracers (BC_sulfate, OC_sulfate, sea salt_sulfate, and dust_sulfate) to keep track of the bulk sulfate mass associated with BC, OC, sea salt, and dust, respectively. The amount of nitrate and ammonium associated with sulfate is calculated with the ISORROPIA thermodynamic equilibrium model. Compared to the simulation of WRF-Chem using CBM-Z, 85 additional tracers have been added into WRF-Chem + APM to improve simulations of the aerosol processes in WRF-Chem.

In the present study, we do not consider the condensation of low volatile secondary organic gases (SOG) onto seed aerosols which will lead to the under-prediction of particle growth rate. Yu (2011) studied the contribution of successive oxidation aging and kinetic condensation of organic compounds to particle growth and pointed out that this process can significantly increase the growth rates of nucleated particles, which is consistent with many field measurements and important for properly accounting for the contribution of nucleated particles to $\mathrm{CCN}$. Further research is needed to include the recently developed extended SOA formation mechanism (Yu, 2011) into WRF-Chem + APM.

\subsubsection{Key microphysical processes controlling particle size distributions}

\section{Nucleation}

Nucleation plays a vital role in controlling particle number distribution and CCN number abundance. The IMN mechanism is adopted in the current study because it is physicallybased and well constrained by laboratory data (Yu, 2006, 2010a). Additionally, not only does it explain the detailed nucleation events observed in boreal forests (Yu and Turco, 2011), it also predicts global nucleation distribution and particle number concentrations consistent (in terms of both spatial patterns and absolute magnitude) with land-, ship-, and aircraft-based observations (Yu et al., 2010). In a more recent study (Yu et al., 2010), we compared the spatial distribution of particle number concentrations predicted by 6 different nucleation schemes to land-, ship-, and aircraft-based measurements, and showed that only the IMN scheme can reasonably account for both absolute values (within a factor of $\sim 2$ ) and spatial distributions of particle number concentrations throughout the troposphere. The strategy to accelerate the calculation of IMN rates is to use pre-generated look-up tables from a detailed kinetic IMN model (Yu, 2010a). Accurate IMN in each grid box can be retrieved from the look-up tables with a simple multiple-variable interpolation subroutine.

It should be noted that the present IMN model considers the binary $\mathrm{H}_{2} \mathrm{SO}_{4}-\mathrm{H}_{2} \mathrm{O}$ system only. Amines and other compounds may affect both neutral and ion-mediated nucleation processes, with the magnitude of the effect depending on the concentrations of these species in the atmosphere. Further research is needed to develop theoretical nucleation models so that the potential impact of amines and other compounds on atmospheric particle formation can be assessed.

\section{Condensation, equilibrium, and coagulation}

The size of existing particles (especially nucleated particles) is changed via the uptake or desorption of precursor gases in the atmosphere. In our study, the condensation of sulfuric acid on particles is explicitly determined, while the uptake of nitrate and ammonium are calculated through thermodynamic equilibrium according to ISOROPIA (Nenes et al., 1998). The amounts of nitrate and ammonium partitioned to sulfate particles in each size bin and sulfate mass coated on the primary particles are assumed to be proportional to the corresponding sulfate mass. With this treatment, our model can consider the contribution of nitrate and ammonium uptake to secondary particle growth.

The mass conserving semi-implicit numerical scheme of Jacobson et al. (1994) is employed to solve the self coagulation of size-resolved sulfate and sea salt particles, as well as the coagulation scavenging of sulfate particles by primary particles. Coagulation is the most time-consuming among 
various size-resolved microphysical processes. To reduce the computing cost of a 3-D sectional aerosol microphysics model, it is important to optimize the coagulation calculation. Here, we have implemented two schemes which substantially reduce the coagulation computing expenses. The first scheme uses pre-generated lookup tables for coagulation kernel calculations and the second one uses a variable time-step for coagulation calculations (Yu, 1998).

\section{Dry and wet deposition}

Dry deposition of aerosols in WRF-Chem + APM is calculated using the updated resistance-in-series approach of Wesely (1989). Size-dependent gravitational settling velocities (Zhang et al., 2001) are also employed in this model. Wet deposition of both trace gases and aerosols is now included in the model. In-cloud and below-cloud wet removal of trace gases and aerosols are considered. For size-resolved sulfate and sea salt particles, we assume that particles larger than the activation diameter are subject to removal via in-cloud scavenging. The removal rate of sulfate and sea salt particles by falling rain droplets are calculated using the sizeresolved washout rate parameterization developed by Henzing et al. (2006), which calculates precipitation scavenging coefficients as a function of aerosol particle size and precipitation intensity. When some of BC, OC, sea salt, and dust are removed from the atmosphere via dry and wet deposition, the corresponding portions of secondary species coated on these particles are also removed.

\subsubsection{Initial conditions}

Proper initial condition is important for atmospheric chemistry and microphysics modeling. It can efficaciously save the spin-up time and provide reasonable background mass and number concentrations to avoid unexpected values which only appear in extreme conditions. In this study, the initial condition for gases and aerosols in WRF-Chem + APM are regridded from GEOS-Chem $+\mathrm{APM} 2^{\circ} \times 2.5^{\circ}$ outputs $(\mathrm{Yu}$ and Luo, 2009) at the date when we begin our simulation. Because both WRF-Chem + APM and GEOS-Chem + APM use the same aerosol microphysics module, the initial number concentrations and particle size distributions at each grid can be readily obtained from GEOS-Chem + APM.

\subsection{Computational cost of the WRF-Chem + APM model}

In this study, all simulations were executed on 8-CPU Linux workstations with the $2.2 \mathrm{Ghz}$ Dual Quad-Core AMD Opteron Processor 2354. The model system was compiled using MPICH2 (http://www.mcs.anl.gov/research/projects/ mpich2/) for parallel processing. When CBM-Z was used, there were 53 gas phase tracers. It took $\sim 2.5 \mathrm{~h}$ computational time for a one day simulation covering a region of $3780 \times 2916 \mathrm{~km}^{2}$ with $27 \mathrm{~km} \times 27 \mathrm{~km}$ horizontal resolutions and 34 vertical layers over the Eastern United States (Table 1). The coupled WRF-Chem + APM model has 138 tracers (53 gases and 85 aerosol species). With full size-resolved microphysics considered (nucleation, condensation, coagulation, deposition, and scavenging) and CBM-Z chemistry, it took the coupled model $\sim 5.5 \mathrm{~h}$ computational time for the same day simulation on the same machine. Such a relatively small increase in computational cost associated with full size-resolved microphysics is desirable. Table 1 also shows the computational costs of two pre-existing aerosol modules in WRF-Chem when aerosol feedback on radiation has been turned off. WRF-Chem + MOSAIC, which has 213 tracers (53 gases and 11 types $\times 8$ aerosol bins and 9 types $\times 8$ cloud bins),took $\sim 15.5 \mathrm{~h}$ computational time for a one day simulation. WRF-Chem + MADE/SORGAM has 110 tracers (42 gases plus 34 aerosol tracers and 34 cloud tracers), and it took $\sim 5.0 \mathrm{~h}$ computational time for a one day simulation. As shown in Table 1, the time cost for each additional tracer associated with aerosol in APM, MOSAIC and MADE/SORGAM simulation is $2.1,4.9$, and $1.7 \mathrm{~min}$, respectively. The computational cost for one day simulation with WRF-Chem + MOSAIC for each additional aerosol tracer is $\sim 2-3$ times of those of the other two aerosol modules.

\section{Simulations and comparisons}

\subsection{Description of model configuration and simulated periods}

For this investigation, WRF-Chem + APM was configured with a horizontal resolution of $27 \mathrm{~km} \times 27 \mathrm{~km}$. The domain covered the middle and eastern United States, extending approximately from latitudes $21.90^{\circ} \mathrm{N}$ to $52.55^{\circ} \mathrm{N}$ and from longitudes $118.05^{\circ} \mathrm{W}$ to $61.98^{\circ} \mathrm{W}$, with 140 grid nodes in the east-west direction and 108 in the north-south direction. The domain extended 34 nodes in the vertical, from the surface to $50 \mathrm{hPa}$, with finer resolution near the surface. Major physics options used include the Rapid Radiative Transfer Model (RRTM) for longwave radiation, the Goddard shortwave radiation scheme, the Noah Land Surface Model (NOAH), the Yonsei University (YSU) planetary boundary layer (PBL) scheme, and the modified Lin cloud microphysics module, and the new Grell scheme for cumulus clouds. Gas-phase atmospheric chemistry in this study is based on the CBM-Z mechanism (Zaveri and Peters, 1999) which uses 67 prognostic species and 164 reactions in a lumped structure approach that classifies organic compounds according to their internal bond types. Rates for photolytic reactions within CBM- $Z$ were derived using the Fast-J scheme. Initial and lateral boundary conditions for meteorological variables were obtained from the NCEP FNL (Final) Operational Global Analysis data on $1^{\circ} \times 1^{\circ}$ degree grids continuously every $6 \mathrm{~h}$ (http://dss.ucar.edu/datasets/ds083.2/). 
Table 1. The comparison of computational costs among different chemistry and aersol schemes in WRF-Chem.

\begin{tabular}{lllllll}
\hline & & & & & & RADM2+MADE/ \\
& WRF & CBM-Z & CBM-Z+APM & CBM-Z+MOSAIC & RADM2 & SORGAM \\
\hline tracers & 0 & 53 & 138 & 213 & 42 & 110 \\
microphysics & no & no & yes & yes & no & yes \\
cost for 1 day simulation & $0.2 \mathrm{~h}$ & $2.5 \mathrm{~h}$ & $5.5 \mathrm{~h}$ & $15.5 \mathrm{~h}$ & $2.0 \mathrm{~h}$ & $4.0 \mathrm{~h}$ \\
time cost for each additional aerosol tracer & & & $2.1 \mathrm{~min}$ & $4.9 \mathrm{~min}$ & & $1.7 \mathrm{~min}$ \\
\hline
\end{tabular}

In this study, we used the up-to-date WRF-Chem + APM model to simulate the spatial and temporal distributions of particle formation and number concentration over the Eastern United States during the period of INTEX-A. The spinup time of our simulations was 15 days (15 June to 30 June 2004). Simulated meteorological and chemical variables were output every hour. All monthly averaged results shown in this paper were simulated for July 2004.

\subsection{Comparisons with the aircraft observations obtained during INTEX-A}

The Intercontinental Chemical Transport Experiment-North America Phase A (INTEX-A) is an integrated atmospheric field experiment performed over North America. It seeks to understand the transport and transformation of gases and aerosols on transcontinental scales and their impact on climate and air quality (Singh et al., 2006). In this work, we used the relevant INTEX-A minute averaged data (downloaded from http://eosweb.larc.nasa.gov/PRODOCS/intexa/ table_intexa.html) to evaluate the WRF-Chem + APM modeling results. INTEXA DC8 data included the aircraft observations of aerosol number concentrations and compositions, along with a suite of meteorological, gas-phase chemistry, and radiative measurements. The measurements of meteorological parameters, chemical tracers and particle number concentrations are used to initially evaluate the aerosol processes simulated by the APM model added to WRFChem. Unless indicated otherwise, model results in this comparison are from the hourly averaged outputs from WRFChem + APM with $27 \mathrm{~km} \times 27 \mathrm{~km}$ horizontal resolution.

\subsubsection{Meteorology}

Local meteorological parameters strongly affect the transport, mixing and chemical processes of both trace gases and aerosols. They are also very important for the WRFChem + APM modeling of microphysics. We therefore begin the results section by briefly comparing predicted and observed meteorological quantities before presenting trace gas and aerosol results from the WRF-Chem + APM simulation. The comparisons presented here suggest that the WRF-Chem + APM configuration employed for this study adequately captured the overall evolution of local meteorology during the simulation period. Figure 1 indicates that the lapse rate of temperature and the vertical gradient of wind speed of observations are well represented by model simulations. The high values of relative humidity in the lower troposphere and the low values in the upper layers are also simulated by the model. The Normalized Mean Error (NME) for temperature and wind speed is -0.003 and 0.004 , respectively. The corresponding Normalized Mean Absolute Error (NMAE) is 0.007 and 0.325 , respectively. Simulated temperature and wind speed are very close to the observations. Temperature shows good agreement with measurements. Correlation between the simulations and observations (4767 samples during the aircraft measurement period) can be high up to 0.996. Simulated wind speed shows good agreement with observations when the wind speeds are high and poor agreement at low wind speeds. Usually, the high wind speed is dominated by the pressure gradient. Good agreement of higher wind speeds means the model can generally capture the meteorological patterns. Lower wind speeds are usually under the control of boundary layer processes which are very hard to predict. The prediction of relative humidity in the model is not as good as temperature and wind speed. The NME and NMAE for relative humidity are -0.116 and 0.37 , respectively. The correlation between the simulations and observations of relative humidity is 0.54 . In this study, simulated RH is lower on average than observed values. Differences in modeled versus observed RH may lead to differences in certain aerosol microphysical processes (nucleation, equilibrium partition, hygroscopic growth...) and the amount of water associated with aerosols which may affect aerosol physical properties.

\subsection{2 $\mathrm{SO}_{2}$ and $\mathrm{CN10}$ concentrations}

Trace gas mixing ratio $\left(\mathrm{SO}_{2}\right)$ and aerosol number concentration (CN10) measurements from the INTEXA DC8 aircraft observations from 6 July through 14 August are presented with observed values along the flight paths in Figs. 2a and 3a, respectively. The available aircraft observations cover most regions over the Eastern United States from the land surface to $12 \mathrm{~km}$. 

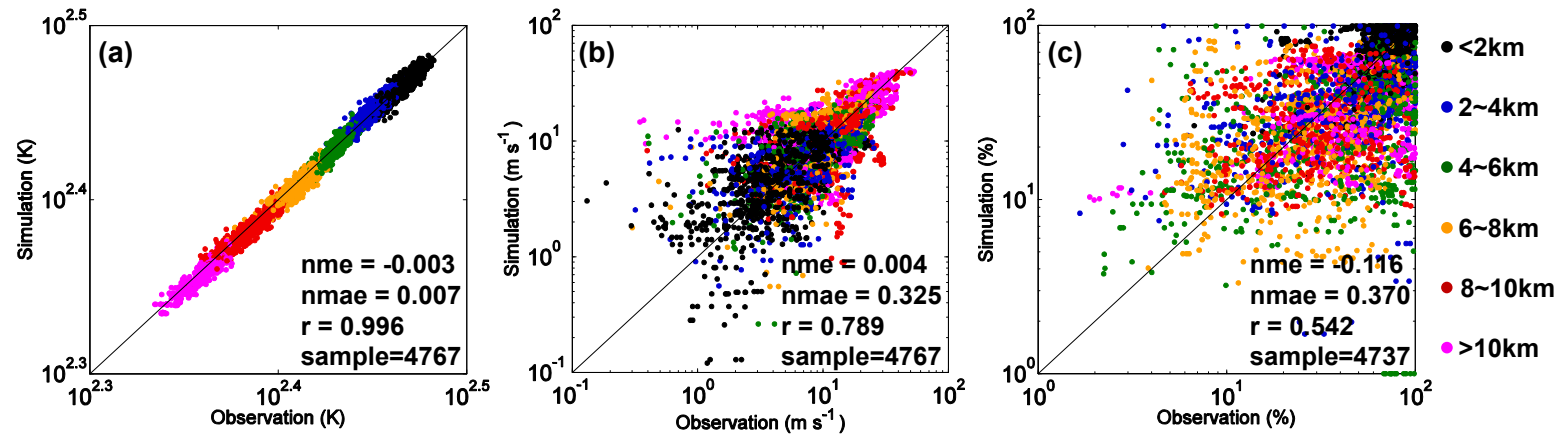

Fig. 1. Scatter diagrams of meteorological parameters simulated by WRF-Chem + APM and the aircraft observations obtained during INTEX-A (6 July to 14 August 2004): (a) temperature; (b) wind speed; (c) relative humidity. The aircraft observations are obtained from minute averaged data of INTEXA DC8. The simulations are obtained according to the date-time and location of each observation along the flight paths. The output of WRF-Chem + APM is an hourly mean.
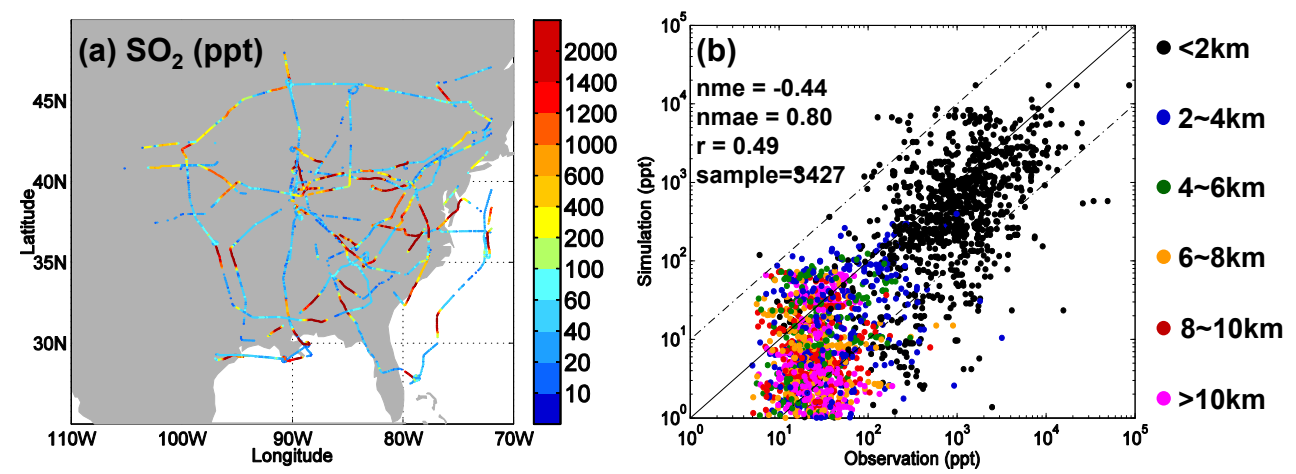

Fig. 2. Comparison of $\mathrm{SO}_{2}$ simulated by WRF-Chem + APM and the aircraft observation obtained during INTEX-A: (a) observed SO $\mathrm{I}_{2}$ by aircraft, view from the top; (b) scatter diagram of the observed and simulated $\mathrm{SO}_{2}$.

The comparison between observed and simulated $\mathrm{SO}_{2}$ along the flight paths is shown in Fig. 2b. Observed high concentrations of $\mathrm{SO}_{2}$ are mainly located in the lower boundary layer $(\sim 1 \mathrm{~km})$ with peak values exceeding $2000 \mathrm{ppt}$. Because the Eastern United States region includes numerous power plants with significant $\mathrm{SO}_{2}$ emissions, surface concentrations of $\mathrm{SO}_{2}$ are much higher than values in the upper troposphere. The concentration of $\mathrm{SO}_{2}$ drops to $\sim 10-100 \mathrm{ppt}$ in the free atmosphere although some values in the lower troposphere $(2-6 \mathrm{~km})$ can still increase up to $\sim 400 \mathrm{ppt}$. The model simulations capture the major characteristics of vertical gradients of $\mathrm{SO}_{2}$ along the flight paths, however, in the upper troposphere, simulated $\mathrm{SO}_{2}$ values are much lower than the observations. Figure $2 b$ shows that the $\mathrm{NME}$ of $\mathrm{SO}_{2}$ for the 3427 aircraft measured samples is $-0.44 \mathrm{ppt}$ and the correlation coefficient between observations and simulations is 0.49 . When the $\mathrm{SO}_{2}$ concentration is low $(<100 \mathrm{ppt})$, the underprediction of simulated $\mathrm{SO}_{2}$ can be high, up to a factor of $\sim 10-100$. Uncertainties in surface emission, $\mathrm{SO}_{2}$ oxidation, vertical transport, and other boundary layer processes could all contribute to the under-prediction of $\mathrm{SO}_{2}$ in the upper tro- posphere. The comparison of observed and simulated sulfate as shown in Fig. 3b indicates that simulated sulfate in the lower troposphere $(<2 \mathrm{~km})$ shows good agreement with observations. Similar to that for $\mathrm{SO}_{2}$, WRF-Chem + APM also under-predicts sulfate concentration in the upper troposphere.

The main source of small particles in the free atmosphere is the nucleation process which highly depends on the oxidation of gaseous $\mathrm{SO}_{2}$ to sulfuric acid, surface area of preexisting particles, temperature, relative humidity, and ion concentration. If a model under-predicts $\mathrm{SO}_{2}$ mixing ratios and relative humidity, it will likely under-predict the formation of atmospheric freshly nucleated particles and may affect the aerosol microphysical processes (such as condensation and coagulation) which in turn impact number concentrations of condensation nuclei. The comparison between observed and simulated $\mathrm{CN} 10$ is presented in Fig. 4. As shown in Fig. 4b, the NME and NMAE for CN10 (4623 aircraft observation samples) are -0.24 and 0.73 , respectively. And the correlation between observations and simulations is 0.61. When CN10 number concentrations are within the 

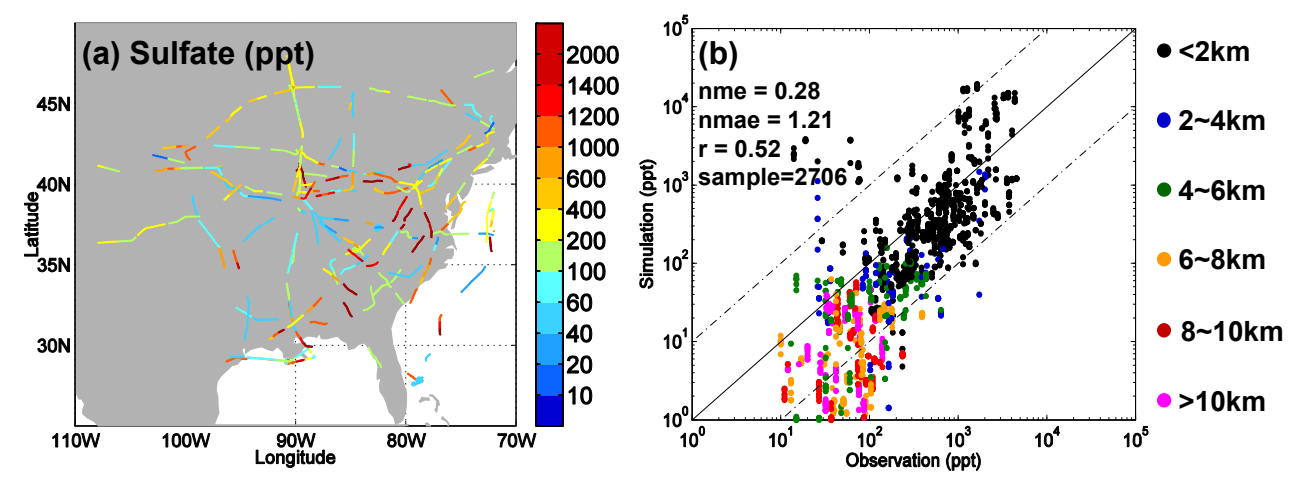

Fig. 3. Same as Fig. 2, except for sulfate.
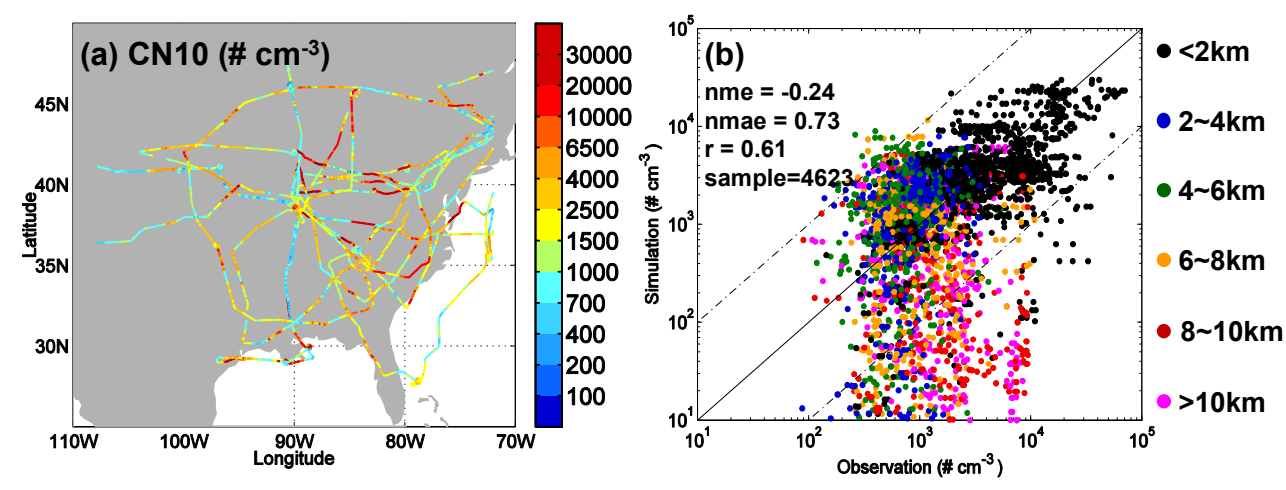

Fig. 4. Same as Fig. 2, except for the number concentration of condensation nuclei larger than $10 \mathrm{~nm}(\mathrm{CN} 10)$.

range of $100-1000 \#^{-3} \mathrm{~cm}^{-3}$ (general value of CN10 in free atmosphere/remote regions), the simulated values are much lower than those observed by aircraft measurements. The deviations of observation and model simulation can increase up to a factor of 10-100. Observations indicate that CN10 is high the in lower boundary layer $(\sim 1 \mathrm{~km})$ and then declines sharply with increasing altitude $(2-6 \mathrm{~km})$. In the upper troposphere $(6-12 \mathrm{~km})$, aircraft observations find some high concentrations of CN10 with values of $\sim 5000 \# \mathrm{~cm}^{-3}$. Figure $4 \mathrm{~b}$ shows that the model can capture the sharply declining CN10 well with increasing altitude under $6 \mathrm{~km}$, but it fails to simulate areas of higher values in the upper troposphere. This behavior is expected, as WRF-Chem + APM significantly under-predicts the $\mathrm{CN} 10$ number concentration in the upper troposphere due to its under-prediction of relative humidity and $\mathrm{SO}_{2}$ in the same regions.

The comparisons of WRF-Chem + APM simulations and the aircraft observations obtained during INTEX-A present a detailed model validation to make quantitative assessment of model performance. The model simulations match well with aircraft measured temperature and wind speed. But the model under-predicts the relative humidity and $\mathrm{SO}_{2}$ mixing ratio in the upper troposphere. These deviations can lead to the under-prediction of new particle formation rates over the corresponding regions which impact $\mathrm{CN} 10$ number concen- trations. Further research is needed to identify the reasons for WRF-Chem's under-prediction of $\mathrm{SO}_{2}$ in the upper troposphere.

\subsection{Simulated particle formation and number concentration in the lower boundary layer}

As shown in Sect. 3.2.1, the WRF-Chem simulations can capture the major characteristics of observed meteorological factors and the spatial-temporal distribution of atmospheric components. It will be interesting to use the model to explore the role of new particle formation in particle number budgets over the Eastern United States.

Figure 5 presents the simulated horizontal (averaged in seven of the lowest model layers representing the boundary layer) monthly mean $\mathrm{SO}_{2}$ mixing ratio, ion-mediated nucleation rate (JIMN), and CN10 by WRF-Chem + APM, WRFChem + APM regrided to the GEOS-Chem + APM scale, and GEOS-Chem + APM. GEOS-Chem + APM has been evaluated by land-, ship-, and aircraft-based measurements (Yu et al., 2008, 2010) and widely used to study the contribution of the formation of secondary particles (i.e. nucleation) and the direct emission of primary particles to atmospheric particle number abundance (Luo and Yu, 2011; Yu and Luo, 2009, 2010). 
(a) WRF-Chem+APM: $\mathrm{SO}_{2}$ (ppb)

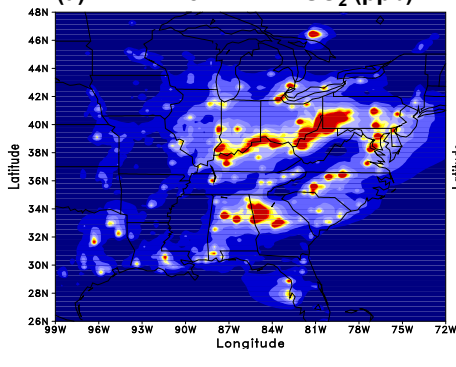

(b) Regrid: $\mathrm{SO}_{2}(\mathrm{ppb})$

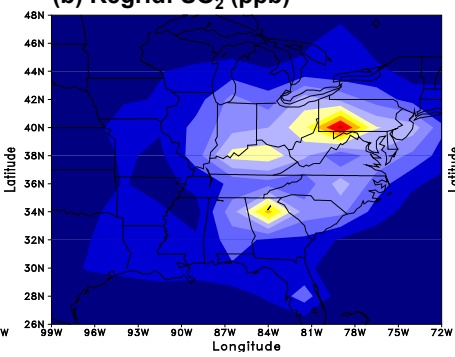

(c) GEOS-Chem+APM: $\mathrm{SO}_{2}$ (ppb)

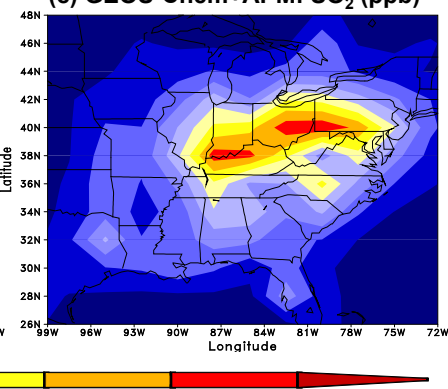

4.5

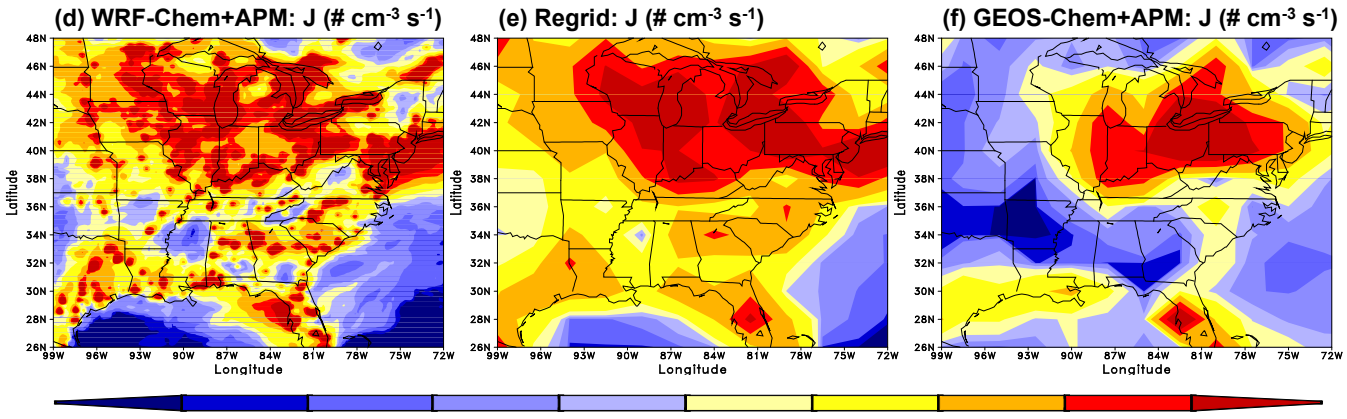

$1 \mathrm{e}-5$ 1e-4 1e-3

(g) WRF-Chem+APM: CN10 (\# cm$\left.{ }^{-3}\right)$

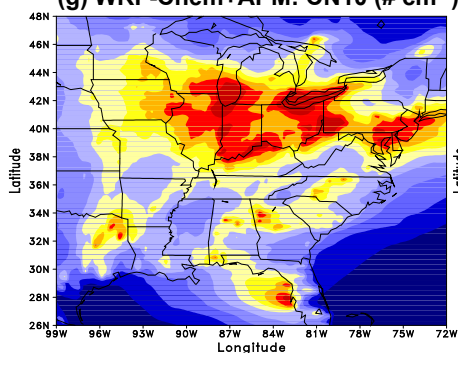

(h) Regrid: CN10 (\# $\left.\mathrm{cm}^{-3}\right)$

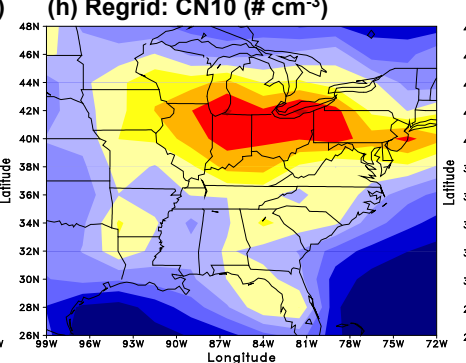

(i) GEOS-Chem+APM: CN10 (\# $\left.\mathrm{cm}^{-3}\right)$

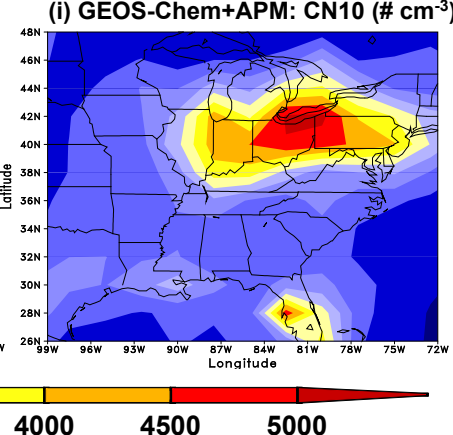

Fig. 5. Simulated horizontal distributions of $\mathrm{SO}_{2}$ concentrations (a, b, $\left.\mathbf{c}\right)$, nucleation rates (d, e, f), and the number concentration of particles larger than $10 \mathrm{~nm}(\mathbf{g}, \mathbf{h}, \mathbf{i})$ in the boundary layer $(\sim 1 \mathrm{~km})$ by WRF-Chem + APM, WRF-Chem + APM regrided to the GEOS-Chem horizontal resolution, and GEOS-Chem + APM (2004 July).

The spatial distribution of July $\mathrm{SO}_{2}$ in the lower boundary layer simulated by WRF-Chem + APM (Fig. 5a) is generally consistent with GEOS-Chem + APM simulations (Fig. 5c), showing that $\mathrm{SO}_{2}$ high concentration is largely confined to the source regions and $\mathrm{SO}_{2}$ concentrations over continents are generally much higher than those within a marine boundary layer. High $\mathrm{SO}_{2}$ concentration zones over Pennsylvania, West Virginia, Ohio, Kentucky and Indiana are reflected in both models. The major difference is that WRF-Chem simulation can capture the high concentration of $\mathrm{SO}_{2}$ plume at urban region for the model's high spatial and temporal resolution. Significant difference of $\mathrm{SO}_{2}$ between urban area and rural area is shown in Fig. 5a. When WRF-Chem + APM simulation results are regrided to the GEOS-Chem + APM scale (Fig. 5b), the high concentrations of $\mathrm{SO}_{2}$ plume at urban region are disappeared. Averaged $\mathrm{SO}_{2}$ high value zones are reflected by the regrided WRF-Chem + APM (Fig. 5b).
Figures $5 \mathrm{~d}-\mathrm{f}$ indicate that IMN in the boundary layer shows a high correlation with the spatial distribution of $\mathrm{SO}_{2}$. At most sources or urban regions, although local pollutants enhance the condensation and coagulation sinks of sulfuric acid, the predicted IMN is still at a very significant level because of the high concentration of residual sulfuric acid over there. Low temperature can also help nucleation occur and thus relatively high nucleation rates are predicted over the Northern regions of the United States by both models.

New particle formation rates, primary particle emissions and particle transport processes contribute to the spatial distribution of $\mathrm{CN} 10$. Figure $5 \mathrm{~g}-\mathrm{i}$ indicates that the regions with high $\mathrm{CN} 10$ values are generally associated with high nucleation zones (Fig. 5d-f), but it is also clear that primary emission and transport processes have substantial impact on $\mathrm{CN} 10$ values in some regions. The gradient of spatial distribution of $\mathrm{CN} 10$ is much smaller than 
that of predicted IMN rates. This indicates that the spatial distribution of CN10 does not depend on new particle formation rates alone. Some high values of CN10 over Texas, Alabama, Georgia, South Carolina and North Carolina are reflected in WRF-Chem + APM but not in GEOS$\mathrm{Chem}+\mathrm{APM}$. This is due to the higher horizontal resolution for WRF-Chem + APM $(27 \mathrm{~km} \times 27 \mathrm{~km})$ than that of GEOSChem + APM $\left(2^{\circ} \times 2.5^{\circ}\right)$. WRF-Chem + APM shows a significant benefit in capturing the high number concentrations of $\mathrm{CN} 10$ in $\mathrm{SO}_{2}$ source regions, especially at those isolated urban/source regions within large remote areas. Figure $5 \mathrm{~h}$ indicates that those high CN10 concentrations shown in WRFChem + APM but not in GEOS-Chem + APM are also reflected in the regrided WRF-Chem + APM results. It means that the sub-grid scale processes not resolved in the global model could actually have an important effect on the predicted aerosol properties in the large scale.

\section{4 $\mathrm{CCN}$ concentration and the contribution of secondary particles in July}

The number of aerosols activated to become cloud droplets depends on particle size distribution, composition, and water vapor supersaturation. Based on the simulated size distributions of secondary particles and primary particles, we can calculate the spatial distribution of CCN concentration at a given supersaturation. In this study, we present the simulated $\mathrm{CCN}$ concentration at supersaturation $=0.4 \%$ (CCN0.4). CCN0.4 is chosen because many CCN measurements gave $\mathrm{CCN}$ at supersaturation $=0.4 \%$ (Andreae, 2009). Figure 6 shows the predicted horizontal and vertical distributions of CCN0.4 and the fraction of secondary particle CCN0.4 in the boundary layer $(0-1 \mathrm{~km})$. Similar to the spatial distribution of $\mathrm{CN} 10$ number concentrations (Fig. $5 \mathrm{~g}-\mathrm{i}$ ), high $\mathrm{CCN} 0.4$ regions in the lower troposphere are generally confined to the $\mathrm{SO}_{2}$ source regions. The highest value of CCNO.4 over the Eastern United States is mainly located in Indiana and Ohio, with peak concentrations exceeding $1600 \mathrm{\#} \mathrm{cm}^{-3}$. This is consistent with high anthropogenic $\mathrm{SO}_{2}$ emissions, new particle formation rates and $\mathrm{CN} 10$ number concentrations over the same region. We also notice that the high values of CCN0.4 over Georgia and Alabama simulated by WRF-Chem + APM is not reflected in the result of GEOS-Chem + APM. Even regrided to the GEOS-Chem scale, the averaged high value zone is still shown in Fig. 6 b. The simulated vertical profiles of CCN0.4 zonally averaged from $72^{\circ} \mathrm{W}$ to $99^{\circ} \mathrm{W}$ by both of WRF-Chem + APM and GEOS-Chem + APM (Fig. 5d-f) indicate that the high value of CCN0.4 concentration is located in the lower troposphere $(0-2 \mathrm{~km})$. CCN0.4 concentration declines sharply with increasing altitude in the free atmosphere. Although WRF$\mathrm{Chem}+\mathrm{APM}$ under-predicts $\mathrm{SO}_{2}$ and $\mathrm{CN} 10$ in the upper troposphere compared to INTEXA DC8 aircraft observations, the impact on CCN0.4 concentration appears to be small.
The present model explicitly resolves secondary particles and primary particles as well as their interactions, enabling us to study the relative contribution of secondary particles versus primary particles to $\mathrm{CCN} 0.4$ concentrations. The secondary fractions of $\mathrm{CCN} 0.4$ as shown in Fig. $6 \mathrm{~g}-\mathrm{i}$ indicate that secondary particles dominate the number abundance in most parts of the Eastern United States. In the lower boundary layer, the secondary fractions of CCNO.4 are generally above $80 \%$ over most regions. The secondary fraction of CCNO.4 over the Southeastern United States simulated by WRF-Chem + APM is a little less than that simulated by GEOS-Chem + APM. It is because we do not include DMS emission in our current work which will underpredict $\mathrm{SO}_{2}$ concentrations and secondary particle formation over the oceans.

\section{Summary and discussion}

The main objective of this study was to simulate the aerosol processes in WRF-Chem by incorporating an advanced particle microphysics (APM) model into the framework of WRFChem and explore the spatial and temporal variations of secondary particle formation (via the ion-mediated nucleation) and its contribution to total particle number concentration and $\mathrm{CCN}$ abundance over the Eastern United States. The computationally efficient APM model has been previously included and validated in GEOS-Chem. The initial number concentrations and particle size distributions at each grid for WRF-Chem + APM simulations are regridded from GEOSChem + APM outputs, substantially reducing the spin-up time. When WRF-Chem + APM were executed on 8-CPU Linux workstations, it took $\sim 5.5 \mathrm{~h}$ computation time for one day simulation covering a region of $3780 \times 2916 \mathrm{~km}^{2}$ with $27 \mathrm{~km} \times 27 \mathrm{~km}$ horizontal resolutions and 34 vertical layers within the Eastern United States. That is merely two times the computing cost of the WRF-Chem using CBM-Z for the same day simulations on the same machine. Such a relatively small increase in the computing cost associated with full size-resolved microphysics is desirable for the detailed aerosol modeling in the framework of WRF-Chem.

Model results of meteorological parameters, chemical tracers and particle number concentrations were validated by the minute averaged aircraft observations obtained during the INTEX-A field campaign in the summer of 2004. The model simulations matched well with aircraft measured temperature and wind speed but under-predicted the relative humidity and $\mathrm{SO}_{2}$ mixing ratio in the upper troposphere. The spatial distribution of $\mathrm{SO}_{2}$ in the lower boundary layer simulated by WRF-Chem + APM for July 2004 was generally consistent with GEOS-Chem + APM simulations and the simulated $\mathrm{SO}_{2}$ concentration in the upper troposphere was largely confined to the source regions. Model simulations indicate that ion-mediated nucleation in the boundary layer shows a high correlation with the spatial distribution of $\mathrm{SO}_{2}$ and it 
(a) WRF-Chem+APM: CCN0.4 (\# $\mathrm{cm}^{-3}$
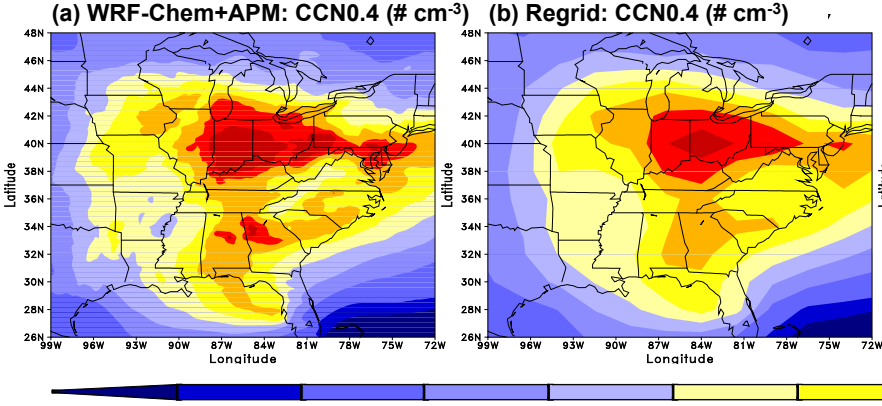

(c) GEOS-Chem+APM: CCNO.4 (\# cm$\left.{ }^{-3}\right)$

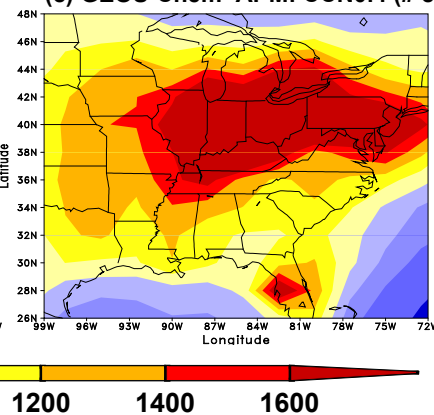

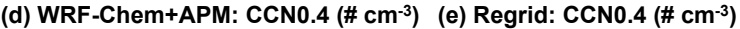
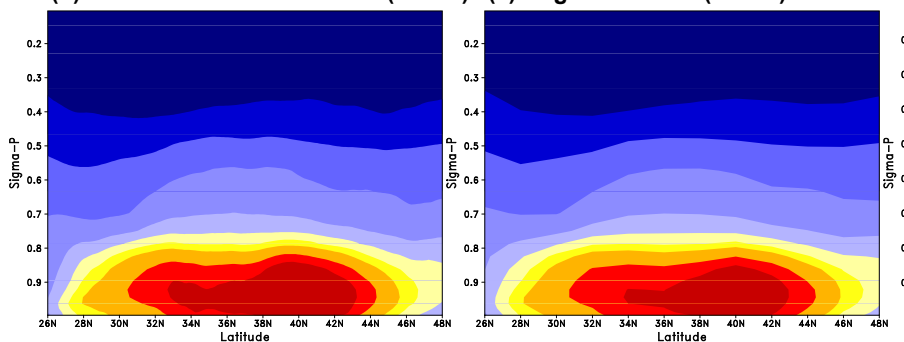

(f) GEOS-Chem+APM: CCN0.4 (\# cm$\left.{ }^{-3}\right)$

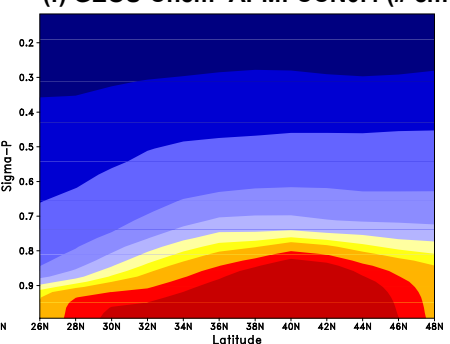

- 1

50

100

200

(g) WRF-Chem+APM: from SP (\%)
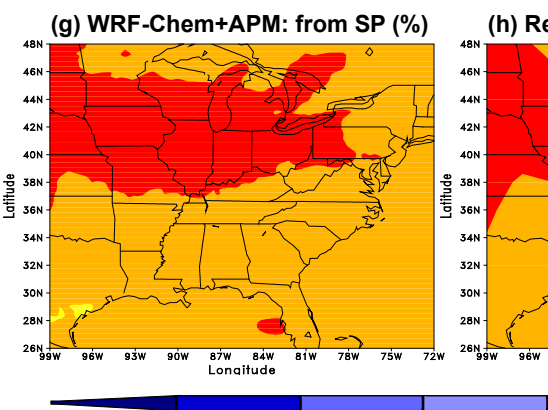

500

10

30

40

50

Fig. 6. (a, b, c) Simulated horizontal distributions of cloud condensation nuclei at water supersaturation ratio of $0.4 \%$ (CCN0.4) in the boundary layer $(\sim 1 \mathrm{~km})$ by WRF-Chem + APM, WRF-Chem + APM regrided to the GEOS-Chem resolution, and GEOS-Chem + APM (2004 July); (d, e, f) simulated vertical profiles of CCN0.4 zonally averaged from $72^{\circ} \mathrm{W}$ to $99^{\circ} \mathrm{W}$; (g, $\left.\mathbf{h}, \mathbf{i}\right)$ same as (a, b, c), except for the fraction of CCN0.4 that is from secondary particles.

dominates the spatial and temporal distributions of CN10. Some high values of CN10 over Texas, Alabama, Georgia, South Carolina and North Carolina are reflected in WRFChem + APM but not in GEOS-Chem + APM. The high resolution WRF-Chem + APM model has a significant advantage in capturing the high $\mathrm{CN} 10$ concentrations in isolated source/urban regions. The highest value of CCN0.4 over the Eastern United States mainly located in Indiana and Ohio, with peak concentrations exceeding $1600 \mathrm{\#} \mathrm{cm}^{-3}$ in July and high value zone confined to the lower troposphere $(0-2 \mathrm{~km})$. Our study shows that secondary particles dominate the CCN number abundance in most parts of the Eastern United States.
While reasonable results with regard to particle formation and number concentration over the Eastern United States have been obtained, the present study is subject to uncertainties and further research are clearly needed to assess the model performance and to reduce uncertainty. Validation with aircraft observations suggest that the WRF-Chem model may under-predict the $\mathrm{SO}_{2}$ mixing ratio and $\mathrm{CN} 10$ number concentrations in the upper troposphere. The underprediction may be caused by errors in convective transport, boundary layer mixing within WRF-Chem and/or particle growth associated with the condensation of secondary organics. In the present study, we do not consider the contribution of SOA to the particle growth. Recent study indicates that the production of low volatile organics from oxidation aging of secondary organic species is necessary in 
order to properly account for the contribution of SOA to particle growth (Yu, 2011). It should be noticed that SOA is likely to important for over the eastern US, especially during summertime. Further research is needed to include the recently developed extended SOA formation mechanism (Yu, 2011) in WRF-Chem + APM. A more comprehensive evaluation of the WRF-Chem + APM model performance by comparing simulated results with various relevant measurements obtained in different regions and seasons should be carried out. A logical next step is to consider aerosol and cloud interaction in the WRF-Chem + APM model to investigate the direct and indirect impacts of aerosol on regional weather and climate.

Acknowledgements. This work has been supported by the US DOE regional modeling program under grant DE-SC0002199. The authors thank the WRF-Chem development and management teams for WRF-Chem version 3.1 used in this study, and the NASA DC-8 team at NASA's Dryden Flight Research Center for the use of INTEX-A aircraft observation data.

Edited by: K. Lehtinen

\section{References}

Andreae, M. O.: Correlation between cloud condensation nuclei concentration and aerosol optical thickness in remote and polluted regions, Atmos. Chem. Phys., 9, 543-556, doi:10.5194/acp-9-543-2009, 2009.

Albrecht, B. A.: Aerosols, cloud microphysics and fractional cloudiness, Sciences, 245, 1227-1230, 1989.

Atwater, M. A.: Planetary albedo changes due to aerosols Science, 170, 64-66, 1970.

Chapman, E. G., Gustafson Jr., W. I., Easter, R. C., Barnard, J. C., Ghan, S. J., Pekour, M. S., and Fast, J. D.: Coupling aerosolcloud-radiative processes in the WRF-Chem model: Investigating the radiative impact of elevated point sources, Atmos. Chem. Phys., 9, 945-964, doi:10.5194/acp-9-945-2009, 2009.

Clarke, A. and Kapustin, V.: Hemispheric Aerosol Vertical Profiles: Anthropogenic Impacts on Optical Depth and Cloud Nuclei, Science, 329, 1488-1492, 2010.

Charlson, R. J., Schwartz, S. E., Hales, J. M., Cess, R. D., Coakley, J. A. J., Hansen, J. E., and Hofmann, D. J.: Climate forcing by anthropogenic aerosols, Science, 255, 423-430, 1992.

D'Almeida, G. A.: On the variability of desert aerosol radiative characteristics, J. Geophys. Res., 92, 3017-3026, 1987.

Dusek, U., Frank, G. P., Hildebrandt, L., Curtius, J., Schneider, J., Walter, S., Chand, D., Drewnick, F., Hings, S., Jung, D., Borrmann, S., and Andreae, M. O.: Size matters more than chemistry for cloud nucleating ability of aerosol particles, Science, 312, 1375-1378, 2006.

Fast, J. D., Gustafson Jr., W. I., Easter, R. C., Zaveri, R. A., Barnard, J. C., Chapman, E. G., Grell, G. A., and Peckham, S. E.: Evolution of Ozone, Particulates and Aerosol Direct Radiative Forcing in the Vicinity of Houston Using a Fully Coupled Meteorology-Chemistry-Aerosol Model, J. Geophys. Res., 111, D21305, doi:10.1029/2005JD006721, 2006.
Gong, S.: A parameterization of sea-salt aerosol source function for sub- and super-micron particles, Global Biogeochem. Cy., 17, 1097, doi:10.1029/2003GB002079, 2003.

Gustafson Jr., W. I., Chapman, E. G., Ghan, S. J., Easter, R. C., Fast, and J. D.: Impact on Modeled Cloud Characteristics Due to Simplified Treatment of Uniform Cloud Condensation $\mathrm{Nu}$ clei During NEAQS 2004, Geophys. Res. Lett., 34, L19809, doi:10.1029/2007GL030021, 2007.

Henzing, J. S., Olivié, D. J. L., and van Velthoven, P. F. J.: A parameterization of size resolved below cloud scavenging of aerosols by rain, Atmos. Chem. Phys., 6, 3363-3375, doi:10.5194/acp-63363-2006, 2006.

IPCC: Climate Change 2007: The Physical Scientific Basis, edited by: Solomon, S., Qin, D., Manning, M., Chen, Z., Marquis, M., Averyt, K. B., Tignor, M., and Miller, H. L., Cambridge Univ. Press, New York, USA, 2007.

Jacobson, M. Z. and Turco, R. P.: Simulating condensational growth, evaporation and coagulation of aerosols using a combined moving and stationary size grid, Aerosol Sci. Tech., 22, 73-92, 1995.

Jacobson, M. Z., Turco, R. P., Jensen, E. J., and Toon, O. B.: Modeling Coagulation Among Particles of Different Composition and Size, Atmos. Environ., 28, 1327-1338, 1994.

Kulmala, M., Riipinen, I., Sipila, M., Manninen, H. E., Petaja, T., Junninen, H., Dal Maso, M., Mordas, G., Mirme, A., Vana, M., Hirsikko, A., Laakso, L., Harrison, R. M., Hanson, I., Leung, C., Lehtinen, K. E. J., and Kerminen, V. M.: Toward direct measurement of atmospheric nucleation, Science, 318, 89-92, 2007.

Luo, G. and Yu, F.: Sensitivity of global cloud condensation nuclei concentrations to primary sulfate emission parameterizations, Atmos. Chem. Phys., 11, 1949-1959, doi:10.5194/acp-111949-2011, 2011.

Luo, G., Yu, F., and Wang, Z.: Impact of aerosol on sea surface temperature over the subtropical Atlantic ocean: A potential trigger factor of the NAO phase conversion?, Geophys. Res. Lett., 36, L03708, doi:10.1029/2008GL036035, 2009.

Makkonen, R., Asmi, A., Korhonen, H., Kokkola, H., Järvenoja, S., Räisänen, P., Lehtinen, K. E. J., Laaksonen, A., Kerminen, V.M., Järvinen, H., Lohmann, U., Bennartz, R., Feichter, J., and Kulmala, M.: Sensitivity of aerosol concentrations and cloud properties to nucleation and secondary organic distribution in ECHAM5-HAM global circulation model, Atmos. Chem. Phys., 9, 1747-1766, doi:10.5194/acp-9-1747-2009, 2009.

Napari, I., Noppel, M., Vehkamaki, H. and Kulmala, M.: Parameterization of Ternary Nucleation Rates for H2SO4NH3-H2O Vapors, J. Geophys. Res.-Atmos., 107, 4381, doi:10.1029/2002JD002132, 2002.

Nenes, A., Pandis, S. N., and Pilinis, C.: ISORROPIA: A new thermodynamic equilibrium model for multiphase multicomponent inorganic aerosols, Aquat. Geochem., 4, 123-152, 1998.

Pan, W., Tatang, M. A., McRae, G. J., and Prinn, R. G.: Uncertainty analysis of indirect radiative forcing by anthropogenic sulfate aerosols, J. Geophys. Res., 103, 3815-3823, 1998.

Pierce, J. R. and Adams, P. J.: Uncertainty in global CCN concentrations from uncertain aerosol nucleation and primary emission rates, Atmos. Chem. Phys., 9, 1339-1356, doi:10.5194/acp-91339-2009, 2009.

Pincus, R. and Baker, M.: Precipitation, Solar Absorption, and Albedo Susceptibility in Marine Boundary Layer Clouds, Na- 
ture, 372, 250-252, 1994.

Schell, B., Ackermann, I. J., Hass, H., Binkowski, F. S., and Ebel, A.: Modeling the formation of secondary organic aerosol within a comprehensive air quality model system, J. Geophs. Res., 106, 28275-28293, 2001.

Singh, H. B., Brune, W. H., Crawford, J. H., Jacob, D. J., and Russell, P. B.: Overview of the summer 2004 Intercontinental Chemical Transport Experiment -North America (INTEX-A), J. Geophys. Res., 111, D24S01, doi:10.1029/2006JD007905, 2006.

Spracklen, D. V., Pringle, K. J., Carslaw, K. S., Chipperfield, M. P., and Mann, G. W.: A global off-line model of size-resolved aerosol microphysics: II. Identification of key uncertainties, Atmos. Chem. Phys., 5, 3233-3250, doi:10.5194/acp-5-3233-2005, 2005.

Spracklen, D. V., Carslaw, K. S., Kulmala, M., Kerminen, V.-M., Mann, G. W., and Sihto, S.-L.: The contribution of boundary layer nucleation events to total particle concentrations on regional and global scales, Atmos. Chem. Phys., 6, 5631-5648, doi:10.5194/acp-6-5631-2006, 2006.

Spracklen, D. V., Carslaw, K. S., Kulmala, M., Kerminen, V. M., Sihto, S. L., Riipinen, I., Merikanto, J., Mann, G. W., Chipperfield, M. P., Wiedensohler, A., Birmili, W., and Lihavainen, H.: Contribution of particle formation to global cloud condensation nuclei concentrations, Geophys. Res. Lett., 35, L16808, doi:10.1029/2007GL033038, 2008.

Stockwell, W. R., Middleton, P., Chang, J. S., and Tang, X.: The second-generation regional acid deposition model chemical mechanism for regional air quality modeling, J. Geophys. Res., 95, 16343-16367, 1990.

Toon, O. B., Turco, R. P., Westphal, D., Malone, R., and Liu, M. S.: A multidimensional model for aerosols: Description of computational analogs, J. Atmos. Sci., 45, 2123-2143, 1988.

Turco, R. P., Hamill, P., Toon, O. B., Whitten, R. C., and Kiang, C. S.: A one-dimensional model describing aerosol formation and evolution in the stratosphere, Part I, Physical processes and mathematical analogs, J. Atmos. Sci., 36, 699-717, 1979.

Twomey, S.: The influence of pollution on the shortwave albedo of clouds, J. Atmos. Sci., 34, 1149-1152, 1977.

Wang, M. and Penner, J. E.: Aerosol indirect forcing in a global model with particle nucleation, Atmos. Chem. Phys., 9, 239-260, doi:10.5194/acp-9-239-2009, 2009.

Wesely, M. L.: Parameterization of Surface Resistances to Gaseous Dry Deposition in Regional-Scale Numerical-Models, Atmos. Environ., 23, 1293-1304, 1989.

Wexler, A. S., Lurmann, F. W., and Seinfeld, J. H.: Modelling Urban and Regional Aerosols - I. Model Development, Atmos. Environ., 28, 531-546, 1994.

Yu, F.: A Study of the Formation and Evolution of Aerosols and Contrails in Aircraft Wakes: Development, Validation and Application of an Advanced Particle Microphysics (APM) Model, Doctoral Dissertation, UCLA, 1998.

Yu, F.: From molecular clusters to nanoparticles: second-generation ion-mediated nucleation model, Atmos. Chem. Phys., 6, 51935211, doi:10.5194/acp-6-5193-2006, 2006.
Yu, F.: Ion-mediated nucleation in the atmosphere: Key controlling parameters, implications, and look-up table, J. Geophy. Res., 115, D03206, doi:10.1029/2009JD012630, 2010a.

Yu, F.: Diurnal and seasonal variations of ultrafine particle formation in anthropogenic $\mathrm{SO}_{2}$ plumes, Environ. Sci. Technol., 44, 2011-2015, doi:10.1021/es903228a, 2010b.

Yu, F.: A secondary organic aerosol formation model considering successive oxidation aging and kinetic condensation of organic compounds: global scale implications, Atmos. Chem. Phys., 11, 1083-1099, doi:10.5194/acp-11-1083-2011, 2011.

Yu, F. and Luo, G.: Simulation of particle size distribution with a global aerosol model: contribution of nucleation to aerosol and CCN number concentrations, Atmos. Chem. Phys., 9, 76917710, doi:10.5194/acp-9-7691-2009, 2009.

Yu, F. and Luo, G.: Oceanic Dimethyl Sulfide Emission and New Particle Formation around the Coast of Antarctica: A Modeling Study of Seasonal Variations and Comparison with Measurements, Atmosphere, 1, 34-50, 2010.

Yu, F. and Turco, R. P.: The role of ions in the formation and evolution of particles in aircraft plumes, Geophys. Res. Lett., 24, 1927-1930, 1997.

Yu, F. and R. P. Turco: Ultrafine aerosol formation via ion-mediated nucleation, Geophys. Res. Lett., 27, 883-886, 2000.

Yu, F. and Turco, R. P.: The size-dependent charge fraction of sub-3-nm particles as a key diagnostic of competitive nucleation mechanisms under atmospheric conditions, Atmos. Chem. Phys., 11, 9451-9463, doi:10.5194/acp-11-9451-2011, 2011.

Yu, F., Luo, G., Bates, T., Anderson, B., Clarke, A., Kapustin, V., Yantosca, R., Wang, Y., and Wu, S.: Spatial distributions of particle number concentrations in the global troposphere: Simulations, observations, and implications for nucleation mechanisms, J. Geophys. Res., 115, D17205, doi:10.1029/2009JD013473, 2010.

Zaveri, R. A. and Peters, L. K.: A new lumped structure photochemical mechanism for large-scale applications, J. Geophys. Res., 104, 30387-30415, 1999.

Zaveri, R. A., Easter, R. C., Fast, J. D., and Peters, L. K.: Model for Simulating Aerosol Interactions and Chemistry (MOSAIC), J. Geophys. Res., 113, D13204, doi:10.1029/2007JD008782, 2008.

Zender, C. S., Bian, H., and Newman, D.: Mineral Dust Entrainment and Deposition (DEAD) model: Description and 1990s dust climatology, J. Geophys. Res., 108, 4416, doi:10.1029/2002JD002775, 2003.

Zhang, L. M., Gong, S. L., Padro, J., and Barrie, L.: A size segregated particle dry deposition scheme for an atmospheric aerosol module, Atmos. Environ., 35, 549-560, 2001.

Zhang, Y., Liu, P., Liu, X.-H., Jacobson, M. Z., McMurry, P. H., Yu, F., Yu, S., and Schere, K. L.: A comparative study of nucleation parameterizations: 2. Three-dimensional model application and evaluation, J. Geophys. Res., 115, D20213, doi:10.1029/2010JD014151, 2010a.

Zhang, Y., McMurry, P. H., Yu, F., and Jacobson, M. Z.: A Comparative Study of Homogeneous Nucleation Parameterizations, Part I. Examination and Evaluation of the Formulations, J. Geophys. Res., 115, D20212, doi:10.1029/2010JD014150, 2010b. 